\title{
Aprendizagem colaborativa interinstitucional: práticas de Educação 5.0 em favor do empoderamento feminino
}

\author{
Daniela Eloise Flôr ${ }^{1,3}$, Eduardo Henrique Molina da Cruz ${ }^{1}$, Ayslan Trevizan Possebom ${ }^{1}$, \\ Carla Santos de Oliveira ${ }^{1}$, André Pinto Moreira ${ }^{2}$, Carlos Roberto Beleti Junior ${ }^{2}$, \\ Ana Paula Vieira Guimarães ${ }^{3}$, Linnyer Beatrys Ruiz Aylon ${ }^{3}$ \\ ${ }^{1}$ Instituto Federal do Paraná Campus Paranavaí \\ Equipe MannaTeam \\ Paranavaí - Paraná \\ ${ }^{2}$ Universidade Federal do Paraná Campus Avançado de Jandaia do Sul \\ Equipe MannaTeam \\ Jandaia do Sul - Paraná \\ ${ }^{3}$ Universidade Estadual de Maringá \\ Equipe MannaTeam \\ Maringá - Paraná \\ \{daniela.flor, eduardo.cruz, ayslan.possebom\}eifpr.edu.br \\ \{carlaoliveira.ifpr, naguimaraes10, moreira.andre.p\}@gmail.com \\ carlosbeleti@ufpr.br, lbruiz@uem.br
}

\begin{abstract}
This paper describes an Education 5.0 experience that engaged universities and public elementary and secondary schools in actions and reflections on gender disparity and the need to increase the female presence in STEAM areas. The results came from the sharing of knowledge, maker spaces and courseware, as well as the expansion of technical training actions and dialogue with society.
\end{abstract}

Resumo. Este artigo descreve uma experiência de Educação 5.0 que engajou universidades e escolas públicas de ensino fundamental e médio em ações e reflexões sobre a disparidade de gênero e a necessidade de aumentar a presença feminina nas áreas do STEAM. Os resultados vieram do compartilhamento de conhecimentos, espaços criativos e materiais didáticos, bem como da ampliação das ações de formação técnica e diálogo com a sociedade.

\section{Introdução}

A inversão de gênero que acometeu algumas profissões nas últimas décadas é destaque em inúmeras reportagens. No artigo "Por que as mulheres desapareceram dos cursos de computação?", [Santos 2018] expõe que, na década de 1970, cerca de 70\% dos alunos do curso de Ciências da Computação do IME (Instituto Militar de Engenharia) eram mulheres. Atualmente, este número não chega a 15\%. Há tempos esse desequilíbrio não é ignorado, e cada vez mais ações são articuladas para aumentar o engajamento feminino na computação. 
Iniciativas como o projeto "Meninas Digitais" e o evento "Women in Information Technology" despertam e fortalecem o interesse de meninas e mulheres em tecnologia e são exemplos que reforçam que aptidão não tem gênero. Igualmente, Instituições de Ensino Superior (IES), por meio dos seus grupos de pesquisas, têm atuado em favor da compreensão e da aproximação do público feminino em STEAM (acrônimo em inglês para as áreas de Ciências, Tecnologia, Engenharia, Artes e Matemática).

Estudos acadêmicos como o apresentado por [Main and Schimpf 2017] se baseiam em uma visão longitudinal sobre a questão da subrepresentatividade, começando pela pré-escola até a inserção no mundo do trabalho após a graduação, em busca de identificar caminhos e intervenções que tendam à inclusão da computação dentro do leque de opções profissionais do radar feminino. Já a pesquisa de [Khan and Wei 2017] se concentra nos aspectos da retenção das mulheres que ingressam em cursos de Ciência da Computação, com especial atenção aos primeiros anos.

Ao encontro dessa proposta, no Brasil, [Bordin et al. 2020] apresentam uma iniciativa que busca estimular a permanência de mulheres em cursos da área da Computação, por meio de uma metodologia de ação de acompanhamento de alunas ingressantes, realizando, por exemplo, palestras e rodas de conversa tendo como protagonistas ex-alunas e mulheres de destaque na área. Alguns argumentos apresentados por [Pereira et al. 2020], como o estigma de profissão masculina, menores salários, preconceito e falta de incentivo familiar são apontados como fatores que estimulam o desequilíbrio.

O tema é contemporâneo e se alinha, acertadamente, com o item "igualidade de gênero"da lista da Organização das Nações Unidas como um dos 17 objetivos para mudar o mundo [ONU 2015]. Inclusive, a sugestão da ONU é providenciar que meninas e mulheres façam uso de tecnologias de informação e comunicação. Mas é preciso ir além, é necessário capacitá-las a criar tais tecnologias e fazer bom uso delas, bem como desenvolverem habilidades e atitudes que causem impacto positivo na sociedade. O projeto MannaAcademy tem essa missão. A proposta é uma força-tarefa do Grupo MannaTeam, membro do INCT NAMITEC, certificado pela SBMicro, com mais de 20 anos de experiência e 196 integrantes que estreitaram parcerias durante suas carreiras, congregando pessoas de dentro e de fora das universidades para discutir representatividade, produzir inovação e causar impacto positivo na sociedade, aspectos da Educação 5.0.

A Educação 5.0 é apresentada por [Flôr et al. 2020] como um ecossistema educacional emancipador, pautado no protagonismo e na inovação. Os autores citam cinco dimensões importantes neste cenário: as hard skills e o comportamento inovador; as softs skills e a emancipação; os espaços de aprendizagem criativa; o protagonismo compartilhado; e, a atuação responsável com base nas competências e habilidades adquiridas.

O projeto, atendido pela Chamada CNPq/MCTIC/MEC no 31/2018 - Meninas nas Ciências Exatas, Engenharias e Computação, obteve recursos para compra de materiais e 21 bolsas exclusivas para mulheres, sendo: 15 de iniciação científica júnior para alunas do ensino médio (ICJr); 3 para professoras prestarem apoio técnico (ATP); e 3 para alunas de graduação (IC). As universidades parceiras definiram as bolsistas de IC e adotaram 5 escolas de educação básica da rede pública de onde vieram as professoras de ATP e as alunas de ICJr. O reforço feminino se avolumou à participação de professores homens, visto que o número reduzido de mulheres também é uma realidade em várias IES. 
Este artigo apresenta um recorte das ações do projeto, enfatizando como representantes da educação básica, dos cursos Técnico em Informática/IFPR, dos cursos de graduação em Licenciatura em Computação/UFPR e Engenharia Elétrica/UEM e de pósgraduação em computação da UEM, orquestraram competências e habilidades comuns à educação STEAM, para compreender e, principalmente, agir em favor do objetivo norteador de empoderar mulheres por meio da capacitação técnica, da inteligência social e do engajamento, conceitos tão presentes na Educação 5.0. O intercâmbio entre sujeitos e saberes de cursos e níveis de ensino diferentes, distantes geograficamente mas convergentes em propósitos, fortaleceu uma rede de aprendizagem colaborativa interinstitucional, que encurtou distâncias para desconstruir o mito de que computação não é coisa de mulher. Este artigo foi organizado de modo a apresentar o público e a forma de atuação na Seção 2, resultados e impactos na Seção 3 e, por fim, as considerações finais.

\section{Público-alvo e formas de atuação do Projeto}

A integração e colaboração entre as três instituições e as escolas de educação básica exigiu da coordenação do projeto uma organização de trabalho desenhada em cinco etapas:(1) Engajamento, (2) Colaboração itinerante, (3) Aprendizagem e Experimentação em Rede, (4) Diálogos extensionistas e (5) Reflexão. Cada uma das etapas envolveu públicos diferentes e teve formas de atuação diversificadas.

\subsection{Engajamento}

A primeira etapa teve como público-alvo a comunidade acadêmica das escolas públicas selecionadas. Na oportunidade foram realizadas reuniões, palestras e avaliação dos espaços físicos e recursos computacionais disponíveis. As visitações contribuíram para sensibilizar os gestores escolares sobre a Educação 5.0 e a inclusão de meninas em STEAM, bem como subsidiou as decisões sobre quais as atividades seriam mais exequíveis em cada escola e como os recursos financeiros recebidos poderiam ser melhor empregados.

\subsection{Colaboração Itinerante}

A etapa de Colaboração Itinerante foi de intenso trânsito dos participantes devido ao deslocamento entre as cidades para que fosse possível conectar as bolsistas de iniciação científica e iniciar a fase de capacitação. O perfil profissiográfico, bem como as particularidades dos cursos envolvidos permitiram introduzir temas como pensamento computacional, eletrônica, automação, robótica e internet das coisas, além da confecção de representações miniaturizadas de componentes eletrônicos e peças de computadores e smartphones. Concomitante à formação técnica das alunas da graduação, aconteceram os encontros de todas as participantes e demais convidados nas IES e nas escolas para estudar e avaliar a representatividade feminina na computação, os espaços ocupados pelas mulheres na atualidade e os reflexos na demanda profissional.

\subsection{Aprendizagem e Experimentação em Rede}

Na etapa de Aprendizagem e Experimentação em Rede, as atividades foram bastante práticas e operacionalizadas a partir da construção modular de um protótipo de casa inteligente conectada à internet das coisas. O objetivo era desenvolver um modelo em escala 

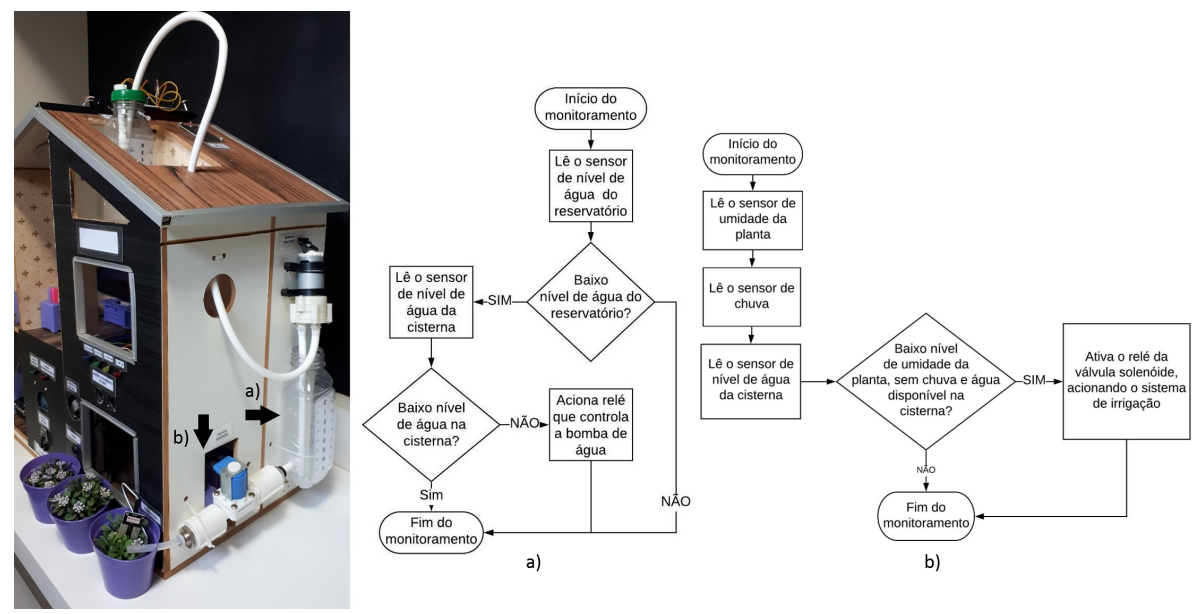

Figura 1. Módulo de captação e abastecimento de água (a) e módulo de irrigação de plantas (b)

reduzida, facilmente transportável, de compreensão instintiva, que pudesse ser apresentado em feiras e exposições como um produto tecnológico resultante do projeto e desenvolvido, exclusivamente, por mulheres.

A modularização do protótipo permitiu que as bolsistas de IC, junto com as bolsistas de ICJr, sob supervisão das professoras de ATP desenvolvessem subsistemas em paralelo que foram integrados posteriormente. Essa estratégia permitiu reduzir a complexidade do desenvolvimento, ao passo que favoreceu que as graduandas ensinassem os conteúdos aprendidos na etapa anterior às alunas do ensino médio.

As bolsistas do IFPR foram responsáveis pelo desenvolvimento dos módulos de: (1) captação e abastecimento de água; (2) irrigação de plantas e solos; (3) energia solar fotovoltaica off grid e o (4) monitoramento de gás. A equipe da UEM/UFPR desenvolveu o módulo de (5) controle de acesso e (6) controle de perímetro.

O módulo de captação e abastecimento de água empregou uma placa ESP32, relé, bomba de água, sensores de nível, além de embalagens descartáveis para reproduzir uma cisterna e um reservatório. O fluxograma da Figura 1(a) detalha o fluxo de execução do bombeamento da água da cisterna para o reservatório, que só acontece quando o sensor de nível informa que há água suficiente para tal. O módulo de irrigação, Figura 1(b), também utilizou portas da mesma placa, além de higrômetro, sensor de umidade de chuva, sensor de nível de água, relé e válvula solenoide.

O controle de emissão de gás, também gerido pelas portas do mesmo ESP32, fez uso de um sensor de gás e um buzzer para emissão de alertas sonoros quando detectado alto nível de emissão de gases inflamáveis ou fumaça, conforme o fluxograma da Figura 2. O sensor utilizado, MQ-2, detecta, experimentalmente, gás natural, metano, propano, butano, GLP e hidrogênio. A sensibilidade é regulada no próprio módulo e os níveis foram configurados no software.

O módulo de energia solar fotovoltaica empregou um kit composto por placa solar e bateria para alimentar lâmpadas e componentes do protótipo. O módulo de controle de acesso, fluxograma da Figura 3, foi gerenciado por uma placa Arduino Mega com o acréscimo de kit de rádio frequência, motor de passos, LEDs, buzzer, relé e lâmpada. As 


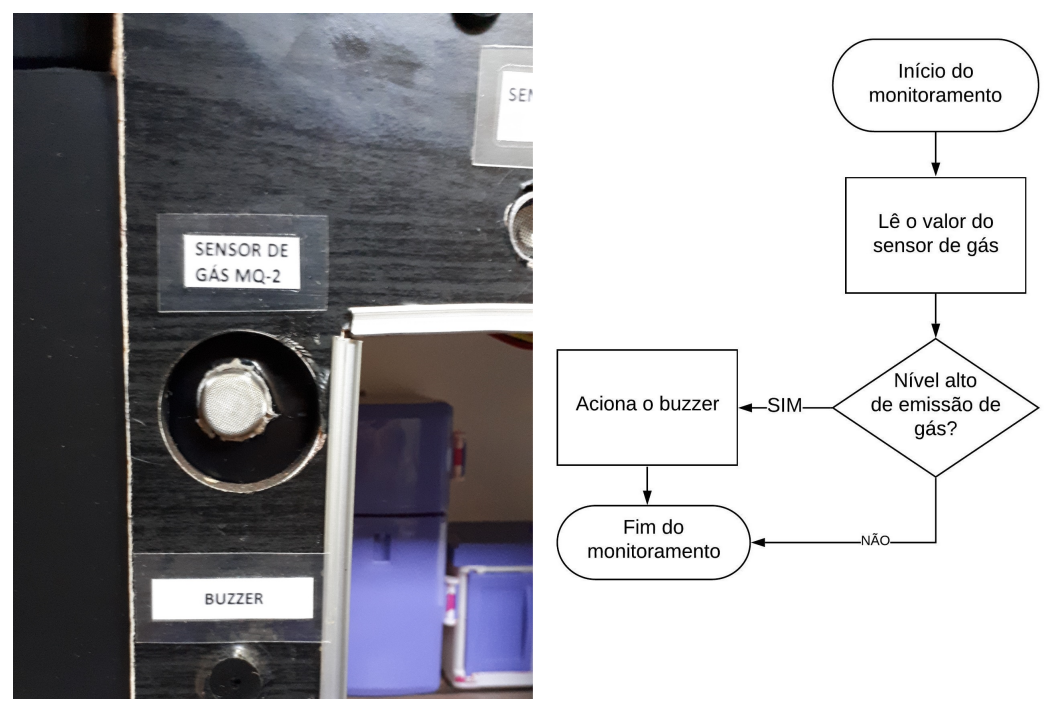

Figura 2. Módulo de monitoramento de emissão de gás
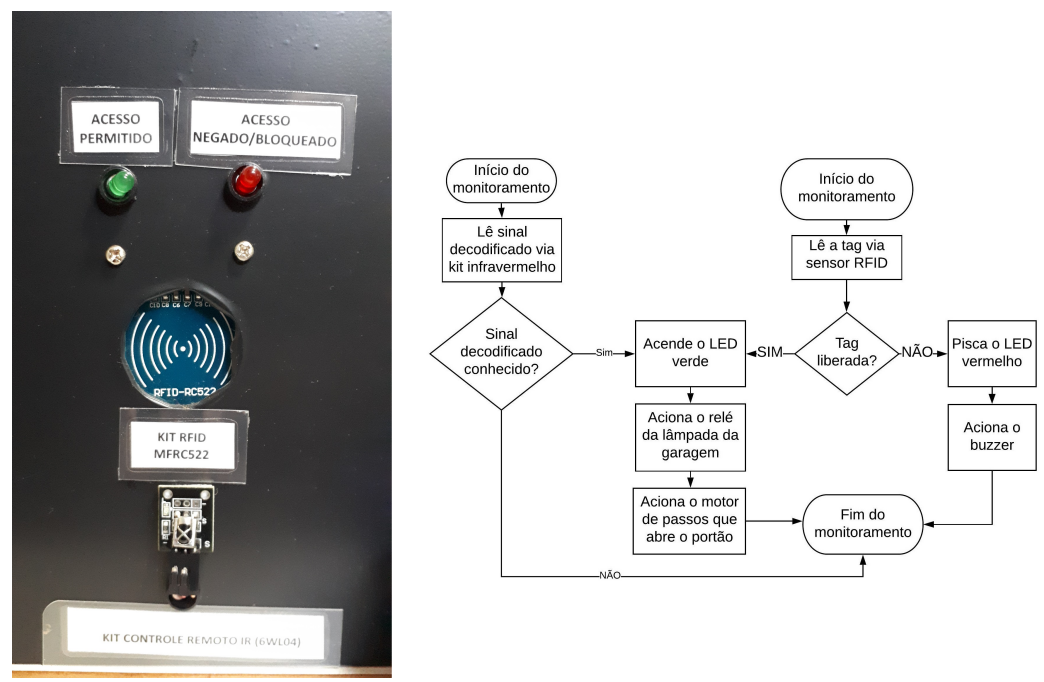

Figura 3. Módulo de controle de acesso

tags liberadas fazem piscar o LED verde, abrir o portão e acionar o relé para acender a luz da garagem. As tags bloqueadas piscam o LED vermelho e acionam o alerta sonoro por meio do buzzer.

Adicionalmente, foi instalado um kit de controle remoto infravermelho para exemplificar o funcionamento de portões eletrônicos. O receptor, ao receber um sinal decodificado, controla o movimento do motor de passos que abre o portão e faz o relé acionar a luz da garagem. Já o monitoramento de perímetro, controlado por um ESP8266, empregou sensor ultrassônico, buzzer, sensor de presença e LDR para evitar aproximações indevidas em determinado período do dia, expresso no fluxograma da Figura 4.

Com o intuito de finalizar a etapa e conectar o protótipo à internet das coisas, os módulos foram unificados. Para tanto, foi utilizada a Arduino IDE, o protocolo MQTT e o broker Mosquitto. Foram desenvolvidas três formas para consultar os dados dos sensores e receber alertas e notificações. A primeira dispôs os dados em um display LCD, na 

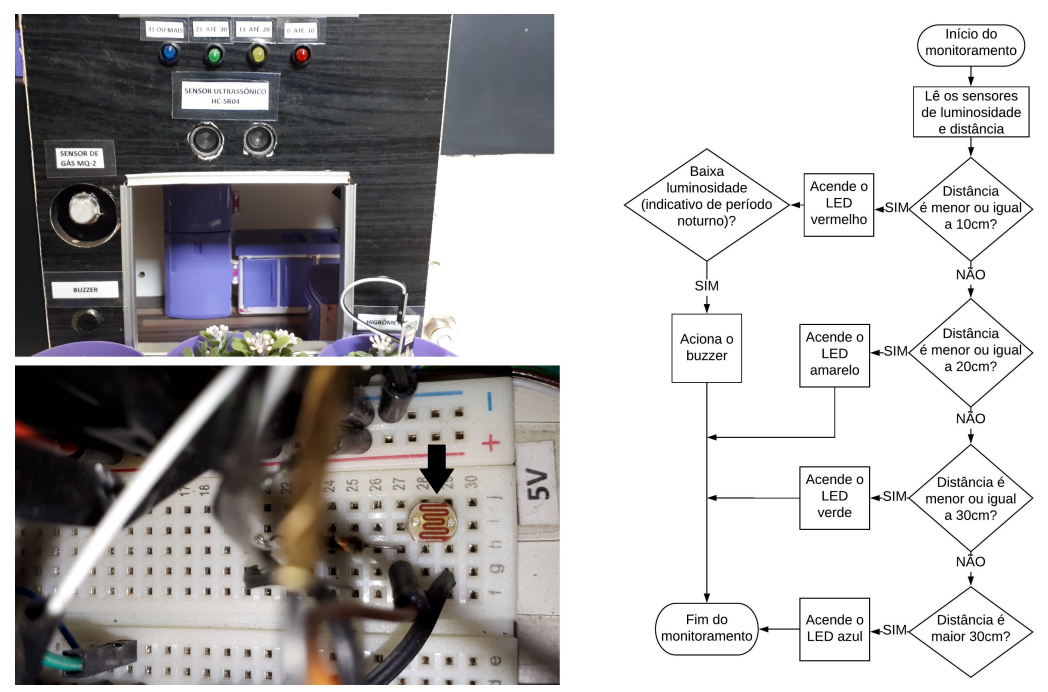

Figura 4. Módulo de monitoramento de perímetro

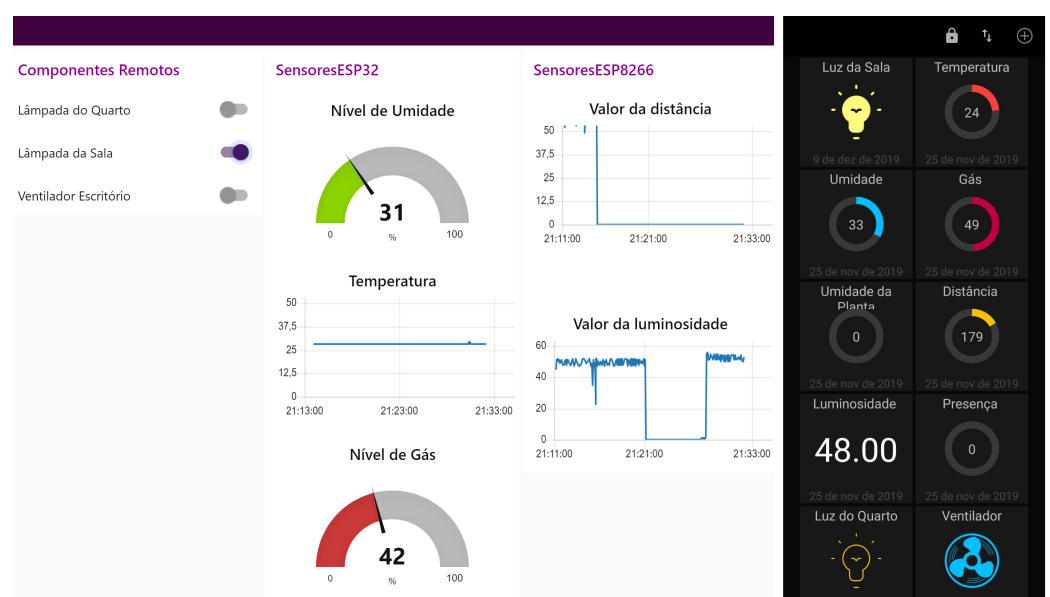

Figura 5. Dashboard Node-Red (esquerda) e Dashboard MQTTDash (direita)

sala do protótipo como se fosse uma televisão. A outra opção foi disponibilizar os dados na web com o Node-RED. O aplicativo MQTTDash permitiu a visualização a partir de celulares Android. A Figura 5 apresenta as versões web e celular.

\subsection{Diálogos Extensionistas}

Fortalecidas com as discussões sobre a atuação feminina na tecnologia e empoderadas pelo conhecimento que permitiu o desenvolvimento de uma prova de conceito de internet das coisas, as participantes adquiriram expertise suficiente para ministrar cursos e oficinas. Professores e alunos das escolas parceiras foram contemplados com oficinas de automação e internet das coisas.

Além disso, as bolsistas estiveram presentes em vários eventos com o intuito de dialogar sobre como meninas e mulheres são capazes de aprender, desenvolver e compartilhar temas nada triviais como os presentes neste projeto. O público diversificado dos eventos exigiu versatilidade de comunicação das bolsistas para se conectarem com os ouvintes, demonstrando maturidade e interesse em serem compreendidas, características relacionadas à Educação 5.0 e evidenciadas como benefícios do projeto. 

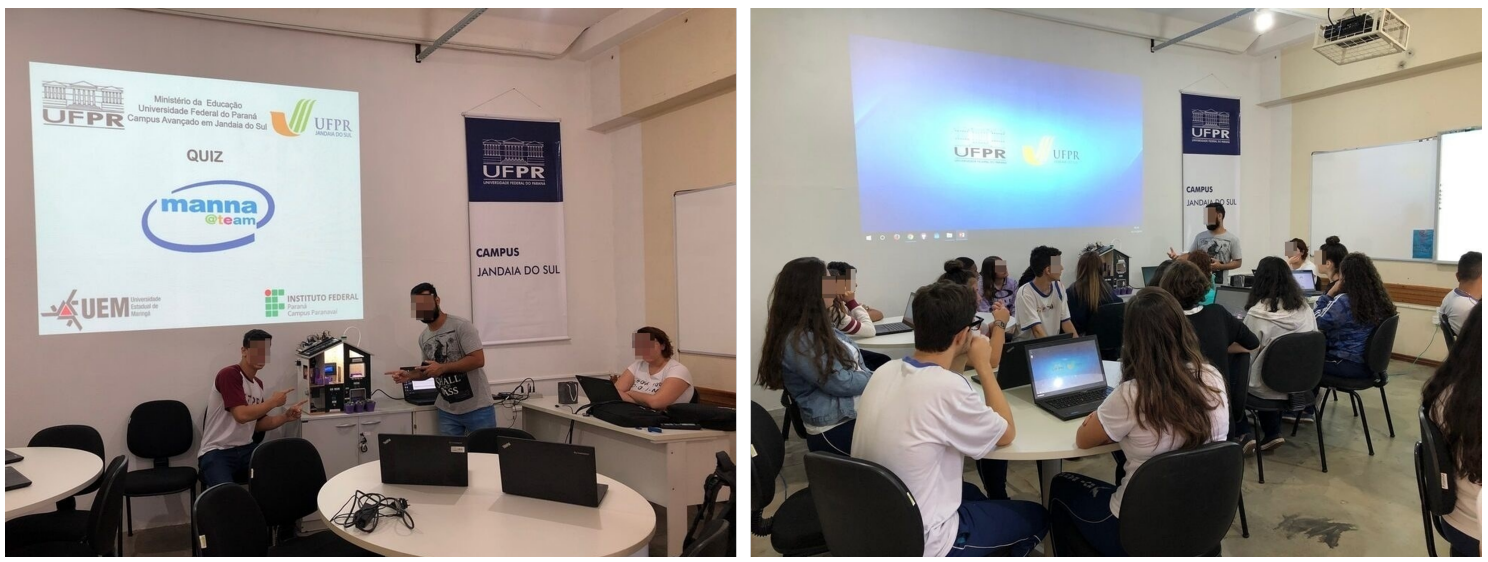

Figura 6. Intervenção educacional

Durante essa etapa o projeto foi convidado a participar de uma intervenção educacional. Para a oportunidade, foram desenvolvidas duas sequências didáticas com duração de 120 minutos. No início foi aplicado um questionário, com o auxílio de um sistema de resposta à audiência (clickers), com o objetivo de verificar o nível de conhecimento dos alunos sobre internet das coisas. Após essa dinâmica, foram abordados os conceitos básicos do tema usando a casa inteligente para exemplificar. Na sequência, foram aplicados experimentos práticos sobre conceitos da disciplina de Física presentes nos sensores ultrassônico e de luminosidade, ou seja, ondulatória e o efeito fotoelétrico.

A intervenção educacional (Figura 6) aconteceu com a participação de um estagiário de Licenciatura em Computação da UFPR, 2 professoras da disciplina de Física e mais 54 alunos de duas turmas do $2^{\circ}$ ano do ensino médio do Colégio Rui Barbosa em Jandaia do Sul.

\subsection{Reflexão e consolidação}

Para conhecer a percepção das bolsistas sobre o projeto, as participantes, de maneira consentida, preencheram um questionário durante a terceira etapa. O questionário abordou as seguintes dimensões: (1) Percepção sobre a atuação feminina em áreas tecnológicas; e, (2) Percepção sobre projetos de engajamento feminino na tecnologia. A realização da pesquisa teve o retorno de 13 bolsistas, do ensino médio e da graduação. Um breve compilado está exposto na Figura 7.

Nas respostas dadas às perguntas da primeira dimensão é possível perceber que uma parcela expressiva das bolsistas $(92,3 \%)$ já tinha noção de que o público feminino era minoria na tecnologia, conforme gráfico da questão 1 . Porém, apenas $23,1 \%$, questão 2 , relataram não vislumbrar oportunidades de trabalho para mulheres; e as três principais razões para tal foram apontadas no gráfico da questão 3 , sendo a naturalização do estereótipo masculino $(76,9 \%)$ a mais expressiva, seguida de falta de encorajamento familiar $(53,8 \%)$ e descrédito dos colegas $(53,8 \%)$.

Merece destaque a compreensão multifacetada que elas desenvolveram sobre a participação no projeto. A bolsista ICJr 1, 15 anos, deu ênfase para o crescimento intelectual, afirmando que "... o contato com componentes eletrônicos, desenvolvimento de circuitos, programação e internet das coisas promovem uma visão diferente para o 


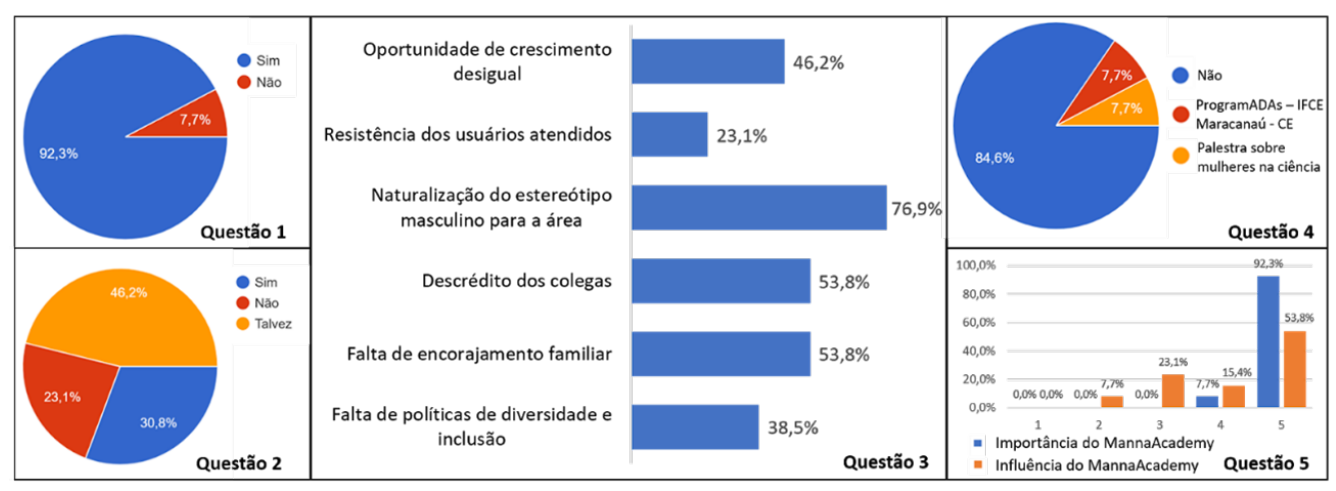

Figura 7. Resultados quantitativos sobre a percepção das bolsistas

estudante e, principalmente para garotas, visto que o conhecimento de uma nova área proporciona um desenvolvimento intelectual maior".

O destaque para a bolsista ICJr 2, 16 anos, foi a característica interdisciplinar do projeto e relata em seu depoimento como o projeto cumpriu seu objetivo primordial: "... durante a participação no projeto obtive conhecimentos da área de física, eletrodinâmica, robótica, programação e eletrônica. Criando em mim o interesse em áreas da tecnologia. E me dando a perspectiva criativa das possibilidades de projetos que posso desenvolver no decorrer de minha vida acadêmica e profissional".

A valorização do papel extensionista está fortemente presente no depoimento da bolsista de iniciação científica de 19 anos, "... com a participação no projeto pude contribuir com as meninas em um período em que estão construindo seus interesses e prestes a tomar decisões quanto ao que cursar na vida acadêmica.".

\section{Resultados e Impactos do Projeto}

O caráter distribuído do projeto causou vários tipos de impactos, seja por meio da oferta de bolsas de iniciação científica, da presença/organização institucional em eventos e palestras ou ainda pelas escolas públicas que foram atendidas por meio de cursos e oficinas. Assim, em 2019 e começo de 2020, foram 120 alunas(os) e 35 professores contemplados da seguinte forma:

- 01 oficina de robótica para alunos do Licenciatura em Computação;

- 04 oficinas de robótica para alunos do ensino médio;

- 01 curso de extensão sobre robótica para alunos do ensino fundamental;

- 02 oficinas de robótica para professores da educação básica;

- 02 oficinas de internet das coisas para alunos do ensino médio e superior;

- 01 curso de extensão sobre internet das coisas para alunos do ensino fundamental.

A Figura 8 registra, à esquerda, momentos de aprendizado durante cursos e oficinas. A mesma figura, à direita, apresenta algumas das participações em eventos, oportunidades em que alunas e alunos de escolas municipais, estaduais e federais, além de empresários dos segmentos da indústria, comércio e agropecuária conheceram o projeto. Alguns desses diálogos com a sociedade ocorreram nos seguintes eventos:

- X Semana Científica, Cultural e Esportiva do Instituto de Educação Estadual de Maringá; 

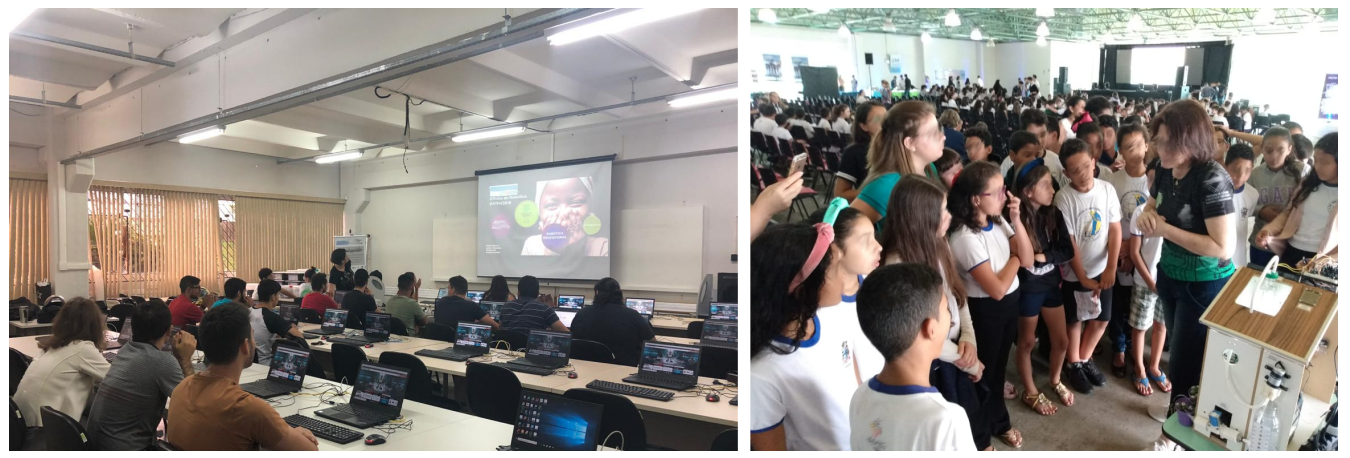

Figura 8. Oferta de cursos (esquerda) e participação em eventos (direita)

- VII Feira de Inovação Tecnológica do IFPR Campus Paranavaí;

- IV Femax - Escola Fatecie Max - Paranavaí;

- II SIPEN - Seminário de Pesquisas do Núcleo Base do IFPR Campus Paranavaí;

- VI SETIF - Semana de Tecnologia da Informação do IFPR - Paranavaí;

- III Simpósio de Licenciaturas em Exatas e Computação - Jandaia do Sul;

- XI SIEPE - Semana Integrada de Ensino, Pesquisa e Extensão - Jandaia do Sul;

- Semana do Meio Ambiente da UFPR;

- Evento de Tecnologias Informacionais no Colégio Vera Cruz - Mandaguari;

- Feira de Cursos e Profissões nos Campi Avançados da UFPR;

- Feira Tecnológica DO Colégio Estadual Unidade Pólo - Jandaia do Sul;

- Mostra Cultural do Colégio Estadual Carlos Silva - São Pedro do Ivaí;

- Visita guiada dos integrantes da Associação Florart Vida - Jandaia do Sul;

- Visita guiada dos alunos do Colégio Vera Cruz - Mandaguari;

- Semana da Computação da Unespar - Apucarana.

\section{Considerações Finais}

Pelo formato distribuído e colaborativo do projeto, intercorrências com sincronização de agendas, alocação de espaço físico e deslocamento foram obstáculos a serem superados. A experiência com o projeto mostrou que o interesse das meninas pelas áreas de STEAM pode ser estimulado. O que precisa são mais iniciativas que as aproximem deste universo em nível escolar oportuno, ou seja, durante o ensino médio, período em que as escolhas profissionais ocupam o imaginário adolescente. E, por isso, a abrangência e a proximidade com o ensino superior, providenciada pelo MannaAcademy, foi oportuna.

O MannaAcademy é um projeto de Educação 5.0 e trabalha temas nada triviais tais como IoT, mas com ênfase na formação cidadã que desenvolve inteligência social que empodera e inclui. Ademais, socializa o conhecimento entre instituições, traz engajamento e promove o surgimento de uma nova geração de mulheres em STEAM conscientes e despertas, inclusive para a Agenda 2030, ou seja, o plano de ação das Nações Unidades que visa a paz, a prosperidade e a parceira entre as pessoas e o planeta. Dentre as metas e objetivos de desenvolvimento sustentável do plano algumas foram bastante articuladas no projeto e nos protótipos, sejam elas: objetivo 4 - Educação de qualidade, 5 - Igualdade de gênero, 6 - Água Potável e saneamento, 7 - Energia limpa e acessível e 11 - Cidades e comunidades sustentáveis. 
Desta forma, verificou-se que fazer parte desse ecossistema de aprendizagem colaborativa, aliada à discussão de problemas reais do planeta, como a equidade de gênero na atuação profissional, só aumentou a relevância da execução do projeto. Indubitavelmente, o projeto contabilizou resultados positivos, e confirma-se a necessidade da continuidade de projetos com o propósito de atração do público feminino para as áreas STEAM, principalmente quando é possível empregar a mobilidade interinstitucional entre professores e estudantes de níveis de ensino diferentes.

Acompanhar, longitudinalmente, as trajetórias acadêmicas e profissionais das bolsistas é uma continuidade valiosa para estudos dessa natureza. O que nem sempre é possível. Mas, os primeiros indicativos, obtidos em 2021, são animadores. Já contabilizamos três ex-bolsistas do ensino médio e uma ex-bolsista de graduação engajadas em outros projetos de IoT, e outra ex-bolsista de graduação atuando como docente de programação. Enfim, saber que cinco mulheres permanecem interessadas e atuando em outros projetos na mesma área, pode ser considerada uma perspectiva promissora.

\section{Agradecimentos}

Este trabalho é patrocinado pelo CNPq/MCTI/MEC (Processos $n^{\circ}$ 426119/2016, 311685/2017-0 e 442433/2018), CAPES (Bolsa PNPD 88887.473183/2020-00), IFPR, UEM, UFPR, UTFPR, IFSP, UNICENTRO, e apoiado pelos membros do MannaTeam.

\section{Referências}

Bordin, A., Finger, A., Gindri, L., and de Mello, A. (2020). Tutoria das gurias: Uma ação de acompanhamento de alunas ingressantes em cursos de computação. In Anais do XIV Women in Information Technology, pages 129-138, Porto Alegre, RS, Brasil. SBC.

Flôr, D. E., Cruz, E. H. M., Possebom, A. T., Beleti Junior, C. R., Hübner, R., and Aylon, L. B. R. (2020). Mannateam: a case of interinstitutional collaborative learning and education 5.0. In Proceedings of the 2020 International Conference on Computational Science and Computational Intelligence (CSCI), pages 964-970.

Khan, A. and Wei, Y. (2017). Free talk zone: Inclusive pedagogy to encourage women in computer science. In Proceedings of the 2017 International Conference on Computational Science and Computational Intelligence (CSCI), pages 1108-1114.

Main, J. B. and Schimpf, C. (2017). The underrepresentation of women in computing fields: A synthesis of literature using a life course perspective. IEEE Transactions on Education, 60(4):296-304.

ONU (2015). Objetivo 5 alcançar a igualdade de gênero e empoderar todas as mulheres e meninas. https://nacoesunidas.org/pos2015/ods5/. Acessado em: 02/06/2021.

Pereira, J., de Moura, L., Coelho, N., Montes, G., Magesti, I. O., and Coelho, A. (2020). Uma análise da participação das mulheres nos cursos técnico em informática e ciência da computação do instituto federal do sudeste de minas gerais. In Anais do XIV Women in Information Technology, pages 139-148, Porto Alegre, RS, Brasil. SBC.

Santos, C. M. (2018). Por que as mulheres "desapareceram" dos cursos de computação? https://jornal.usp.br/universidade/por-que-as-mulheres-desapareceramdos-cursos-de-computacao/. Acessado em: 02/06/2021. 